\title{
MANIFESTAÇÕES PATOLÓGICAS NO PRÉDIO DO IFMS - CAMPUS AQUIDAUANA
}

\author{
POLVERE, RAFAEL \\ Engenheiro Civil \\ IFMS \\ Mato Grosso do Sul; Brasil \\ rafael.polvere@ifms.edu.br
}

\author{
ARANTES, WILKER \\ Estudante de Técnico em Edificações \\ IFMS \\ Mato Grosso do Sul; Brasil \\ wilker.arantes@estudante.ifms.edu.br
}

\section{RESUMO}

O setor construtivo está sempre em movimento, projetos executivos e reformas prediais acabam se tornando ações mais rotineiras. O diferencial de cada execução, está relacionado com a mão de obra utilizada. Entretanto, na maioria dos casos não há um controle de qualidade efetivo no andamento das obras, e com o passar dos anos problemas vão surgindo. Através de um estudo de caso, este artigo visa analisar as patologias existentes em uma Instituição Federal de Ensino, localizada no município de Aquidauana - MS. No campus foi realizado um levantamento das manifestações patológicas encontradas, obtido com questionamentos aos estudantes e servidores, através de registros fotográficos, então assim, procurando identificar e descrever suas prováveis causas e estabelecer suas origens. A instituição analisada, possui mais de 7 anos, mesmo com pouca idade, a edificação apresenta alguns problemas visíveis como o surgimento de trincas, algumas fissuras, manchas, mofos e bolores nas lajes. O estudo permitiu concluir que a maioria das deficiências poderiam ser evitadas durante a execução do projeto.

Palavras-chave: manifestações patológicas, patologias, construção civil.

\section{ABSTRACT}

Throughout Brazil's history, population growth has been rapid, so it's really important to establish institutions that aim to provide quality education and efficiency to the population. For this reason, the Brazilian government seeks this demand building new educational units. However, in most cases, there is no effective quality control in the progress of the works and over the years problems arise. Through a case study, this article aims to analyze the existing pathologies in a Federal Educational Institution, in Aquidauana - MS. On campus a survey of the pathological manifestations found was obtained, through photographic records by students and employees, thus trying to identify and describe their probable causes and establish their origins. The institution analyzed, is over 7 years old, even young, the same presents some visible problems such as the emergence of cracks, stains and molds on the slabs.

Keywords: pathological manifestations, pathologies, construction. 


\section{INTRODUÇÃO}

Desde a evolução do homem, o ser humano vem buscando aperfeiçoar seus materiais e suas técnicas com o intuito de suprir as demandas estruturais das edificações. Com o tempo, o homem por meio da curiosidade, passou a questionar o porquê de certas coisas e começaram a reproduzir o que a natureza lhes proporcionaram.

No final do neolítico e início da Idade do Bronze, por conta da escassez de materiais, com o propósito de melhorar a resistência dos tijolos para as Construções, os fabricantes passaram a reforçar com fibras de vegetais. Em Atenas 437 a.C. há indícios da utilização de ligas metálicas para ganho de resistência estrutural. No período romano, cal e pozolana já eram incorporados como agregados na fabricação do concreto. Isso indica que o homem soube adaptar e evoluir o produto de acordo com as suas necessidades e adequar suas estruturas em diferentes meios. Entretanto, o grande desafio, está em aumentar a durabilidade desse concreto, a fim de reduzir as manifestações patológicas encontradas na grande maioria das construções e encontrar mão me de obra qualificada para a execução dos materiais no canteiro de obras. Segundo POSSAN e DEMOLIER (2013, pág. 1) "Esta deterioração ocorre devido, sobretudo, ao envelhecimento precoce das mesmas, o qual geralmente é desencadeado pela baixa qualidade dos materiais de construção empregados, por problemas de projeto e execução e falta de manutenção."

Nas palavras de Marcelli (2010), quando se manifestaram trincas em elementos de concreto armado, estas devem ser analisadas com cuidado redobrado para sua identificação e solução adequada. $\mathrm{O}$ autor enfatiza que, algumas trincas menos relevantes podem ser desprezadas e solucionadas com métodos convencionais, outras no entanto, demandam um estudo específico, determinando através deste, sua causa, solução, ainda avaliação da necessidade de recuperação ou reforço da estrutura.

Thomaz (1989) adverte que à presença de fissuras deve ser atribuída relativa atenção, pois indica possíveis problemas estruturais, podendo comprometer a segurança da edificação e desconforto aos usuários. Magalhães (2004) acredita que o conhecimento das manifestações patológicas das edificações é de suma importância, desenvolvendo, portanto estudos a cerca do tema, visando a identificação das causas, soluções e métodos preventivos adotados, indicando que haver estudos de casos com identificação das manifestações patológicas apresentadas, assim como de suas causas.

Conforme, Verçoza (1991) a maioria das manifestações patológicas está relacionada à falhas de projeto, seguido, de forma decrescente, por falhas na execução, qualidade de materiais, uso inadequado e planejamento deficiente, como pode ser visto na Figura 1, a qual mostra a porcentagem da distribuição das falhas de acordo com sua origem.

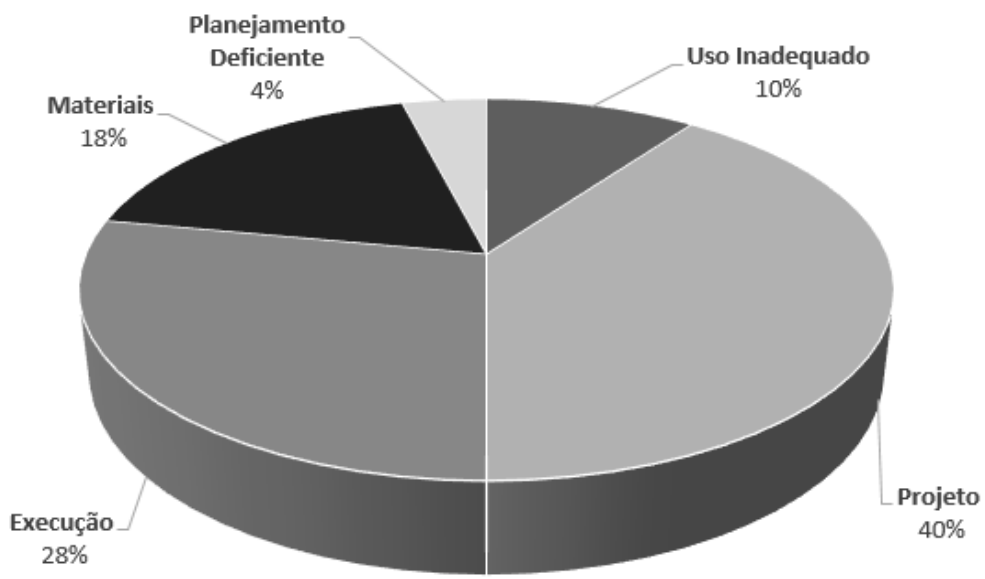

Figura 1: Causas das Manifestações Patológicas.

\section{OBJETIVOS}


Este artigo tem como objetivo apresentar as manifestações patológicas de uma edificação escolar no interior de Mato Grosso do Sul, com a indicação de possíveis causas e apontar sugestões para solucionar os problemas identificados nas alvenarias e nos elementos estruturais. Com 10 anos da construção do instituto, analisou-se o ambiente externo e interno por meio de uma inspeção visual para identificar possíveis falhas e as causas delas.

\section{METODOLOGIA}

\subsection{Características da Edificação}

O Instituto Federal de Educação, Ciência e Tecnologia de Mato Grosso do Sul (IFMS) é uma instituição que faz parte do programa de expansão da Rede Federal de Educação Profissional, Científica e Tecnológica, do Ministério da Educação (MEC). O IFMS - Campus Aquidauana soma a um grupo de 661 instituições federais no Brasil, sendo 10 unidades presentes no estado de Mato Grosso do Sul. Localizado na cidade de Aquidauana, município distante $141 \mathrm{~km}$ da sua capital, Campo Grande, apresenta aproximadamente $32000 \mathrm{~m}^{2}$ (Fig. 2 e 3.). Mesmo possuindo menos de 7 anos de idade, o campus oferta Curso Técnico Integrado em Edificações e Informática, cursos técnicos subsequentes presenciais, o Bacharelado em Engenharia Civil, o curso superior de Tecnologia em Redes de Computadores, além da especialização em Docência para Educação Profissional, Científica e Tecnológica e cursos de qualificação profissional. O local apresenta 4 blocos estruturais, sendo um administrativo (1) e os outros três para fins educacionais (2, 3 e 4).

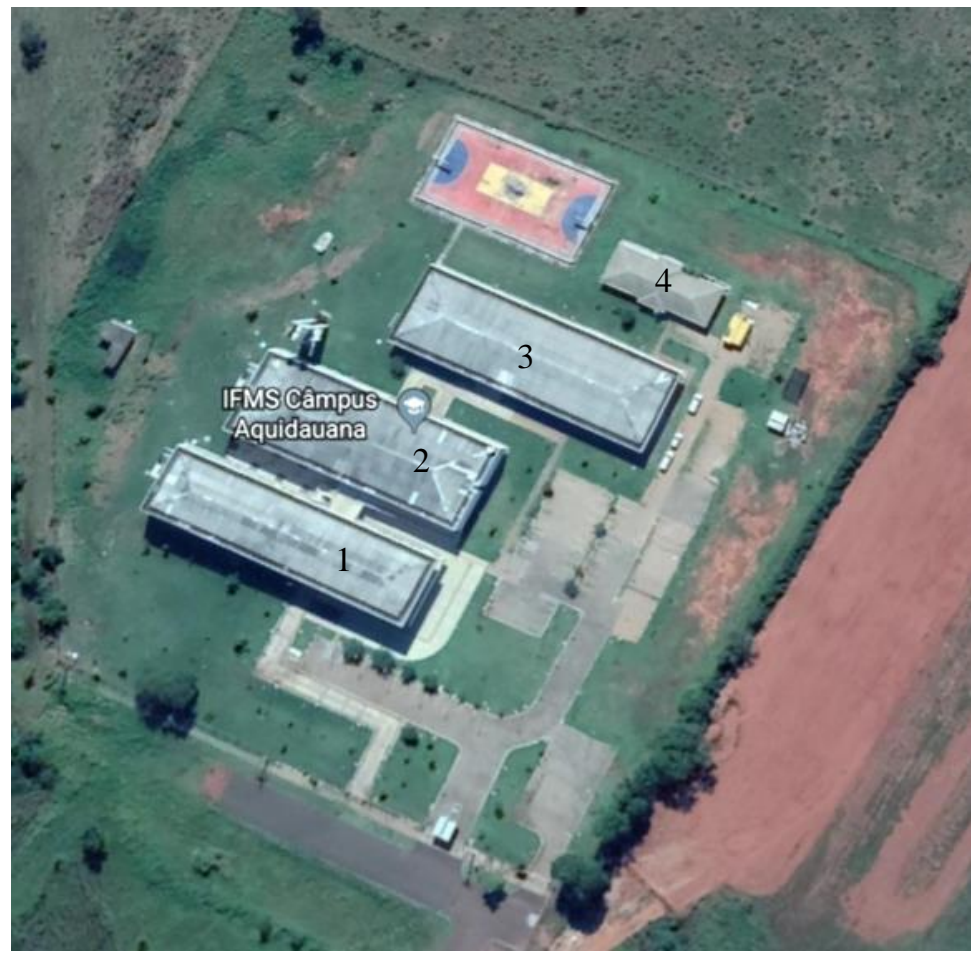

Figura 2: Localização do IFMS - Campus Aquidauana.

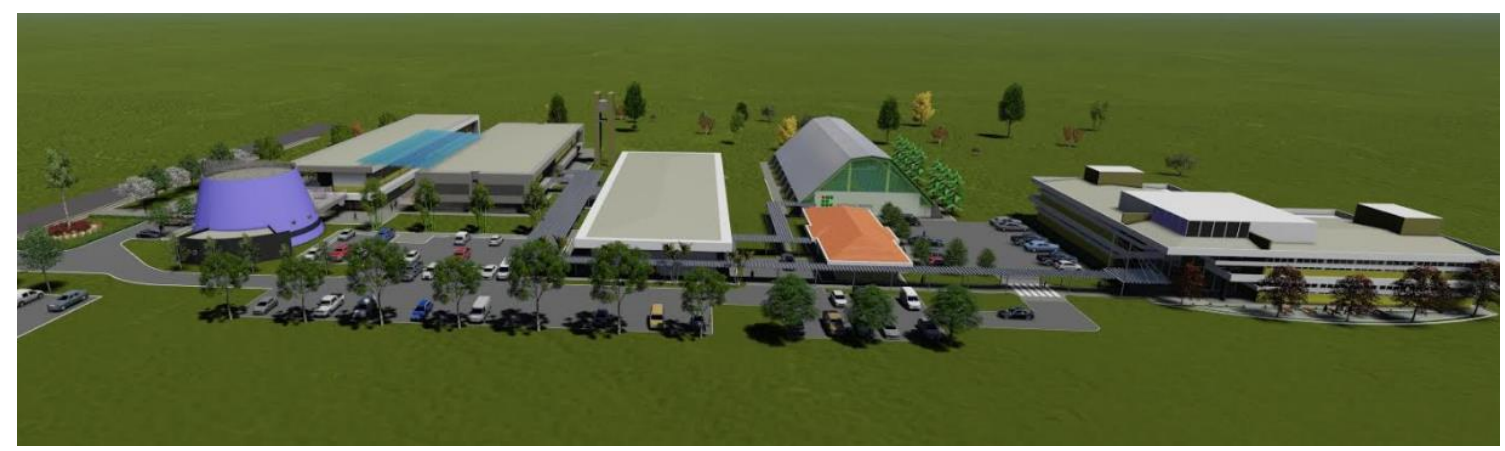

Figura 3: Projeto da Estrutura do IFMS - Campus Aquidauana. 


\subsection{Método}

Foram inspecionados os ambientes internos e externos da instituição e relatado fotogaficamente todas as patologias encontradas. Essa inspeção detalhada da edificação teve objetivo o mapeamento minucioso das manifestações patológicas e danos ocorrentes nas alvenarias e na estrutura do prédio. A partir disso, foram analisados os projetos estruturais, de fundação e outros complementares para ajuda no diagnóstico dos problemas encontrados. Por fim, foram feitas sugestões de intervenção para sanar as patologias encontradas e propriciar um melhor ambiente para os estudantes do Instituto Federal de Mato Grosso do Sul - Campus Aquidauana.

\section{INSPEÇÃO E DISCUSSÃO}

\subsection{Manifestações Patológicas nas Alvenarias}

Foram identificadas fissuras inclinadas em diversas alvenarias em todos os blocos da unidade escolar. Essas fissuras usualmente estavam localizadas próximas aos vãos de portas e janelas, porém, também observou-se em paredes que não possuiam nenhuma abertura. As Figuras “4; 5; 6; 7;” ilustram algumas das situações observadas.

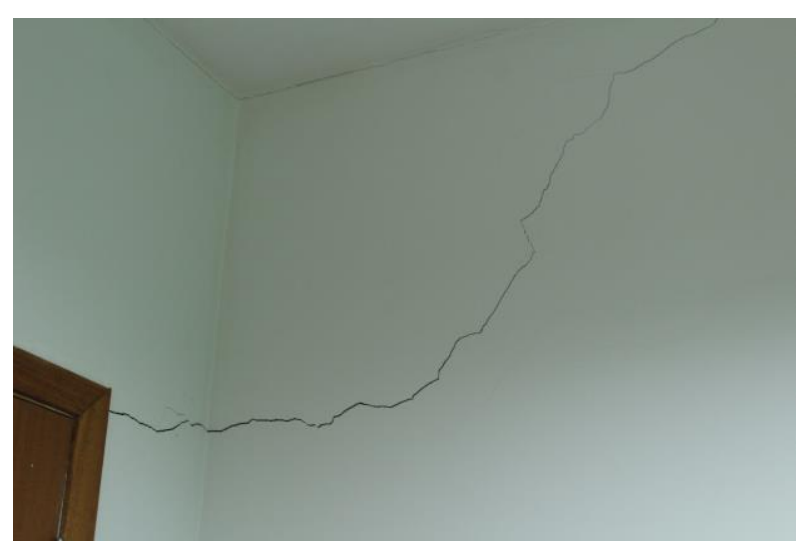

Figura 4: Fissura próxima a porta.

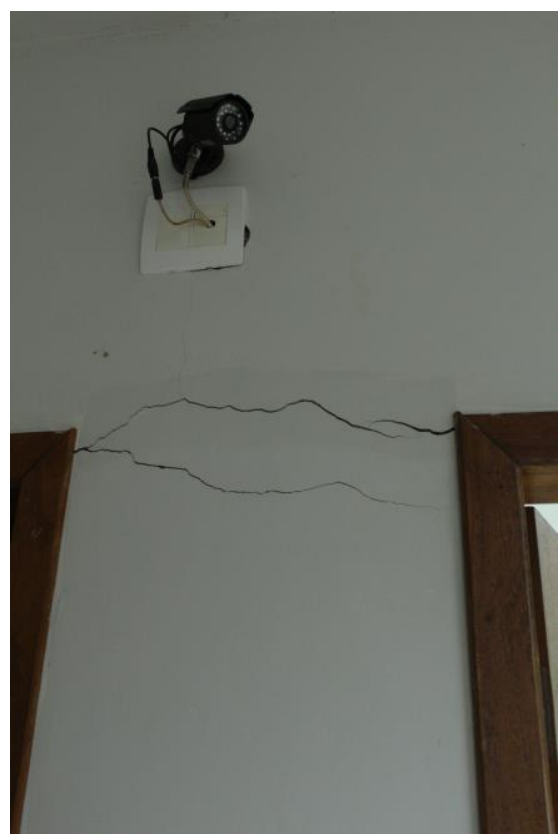

Figura 6: Fissuras próximas a porta.

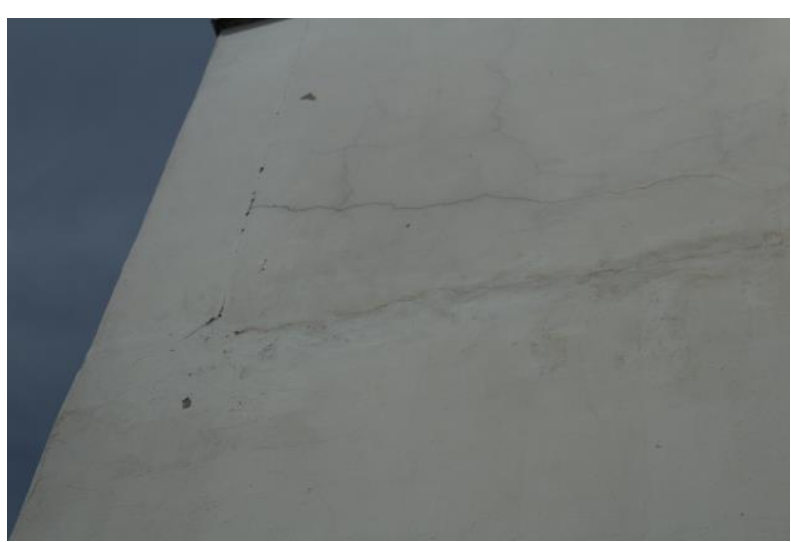

Figura 5: Fissura na fachada.

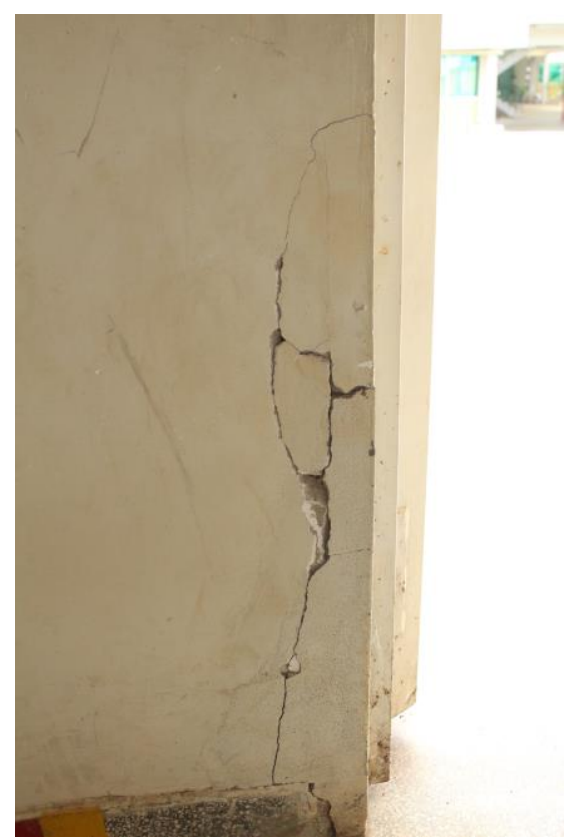

Figura 7: Fissura em parede externa.

As causas possíveis são diversas, por exemplo, nas fissuras em ângulo aproximado de $45^{\circ}$ nos cantos das janelas e portas, pode-se considerar que aconteceu recalque diferencias das fundações. Isso acontece quando há diferença de 
adensamento do solo e as estruturas rebaixam desigualmente. É impossível prever todos os recalques de fundação de uma edificação, por isso, usa-se as vergas e contravergas nas aberturas para minimizas os efeitos, outro possível questionamento de problema nas figuras com fissurações saindo próximas aos vãos de portas e janelas. Essas fissuras posteriormente podem comprometer a parede quanto a problemas decorrentes da infiltração de água, por isso devem ser corrigidas com selagem das fissuras.

Nas Figuras 5 e 7, possivelmente pode ter acontecido retração no concreto, o processo de cura não deve ter sido efetivado como o recomendado, ocorrendo perda muito rápida de água e causando a retração e suas fissuras. Uma boa prática é refazer o revestimento, respeitando os prazos em vigor na norma.

Durante as análises da alvenarias, também foi detectada a presença de agentes biológicos, como colônias de cupins, com isso causando buracos de aproximadamente $2 \mathrm{~mm}$ na estrutura e danificando a estética local. Esses cupins foram encontrados em várias salas de aula da instituição. Mesmo com a dedetização do edifício semestralmente, é possível verificar cotidianamente esses casos na zona na qual o IFMS - Campus Aquidauana se encontra na cidade.

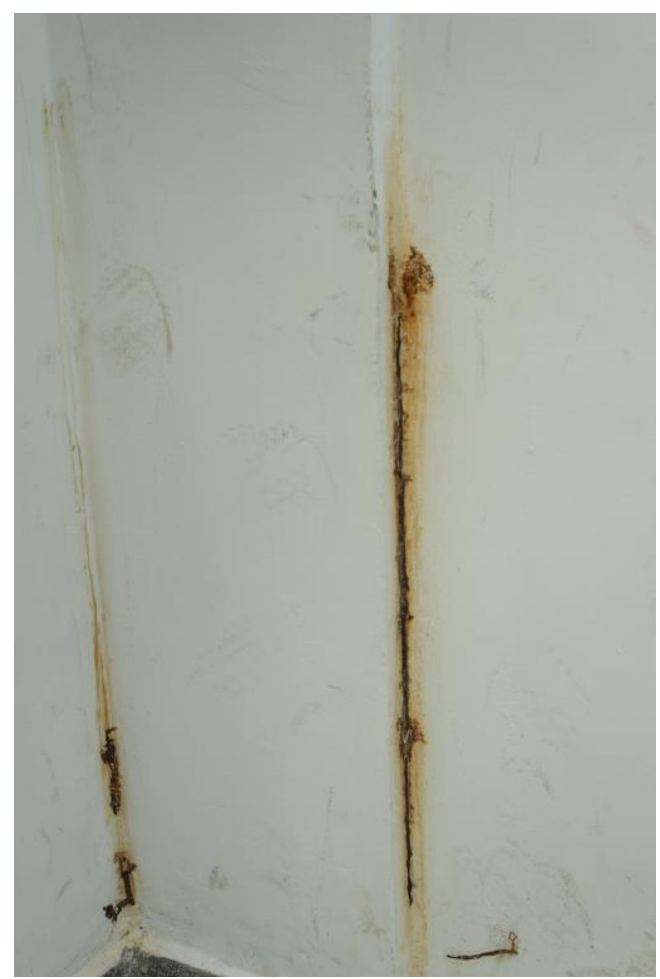

Figura 8: Presença de cupins nas alvenarias

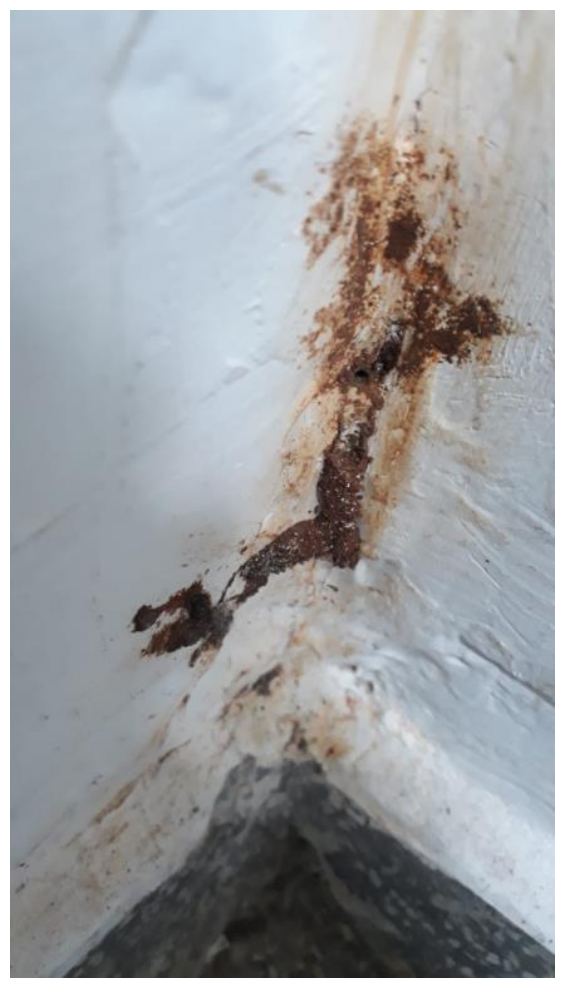

Figura 9: Presença de cupins nas alvenarias

Segundo Vinicius Rocha, esses insetos podem formar estruturas de colônia nas edificações. A veterinária Francinea Souza acrescenta que frequentemente os cupins também fazem esse caminho em busca de alimento através de conduítes, o que causa ainda mais problemas aos imóveis afetados. Ao passarem por estes locais, os bichos produzem uma substância ácida que, somada a restos de fezes e saliva, causa grandes danos ao cabeamento elétrico, acrescentando o risco dos curtos-circuitos à lista de danos — descreve ela. Além disso, quando são altas, as infestações podem comprometer toda a estrutura ou o alicerce da construção, condenando o imóvel pelo consequente risco de desabamento." 


\subsection{Manifestações Patológicas nos Pilares}

Durante as inspeções e observações das manifestações patológicas, os mais encontrados foram fissuras e trincas, na qual, as mais preocupantes foram as manifestações patológicas nos pilares da edificação e na junção das vigas. Essas manifestações estavam em fase avançada, conforme é possível verificar nas Figuras 10 e 11.

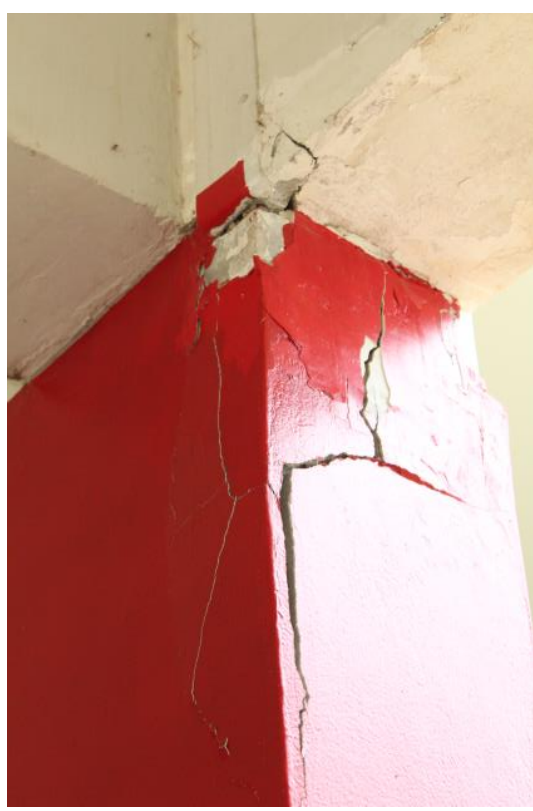

Figura 10: Fissuras no pilar.

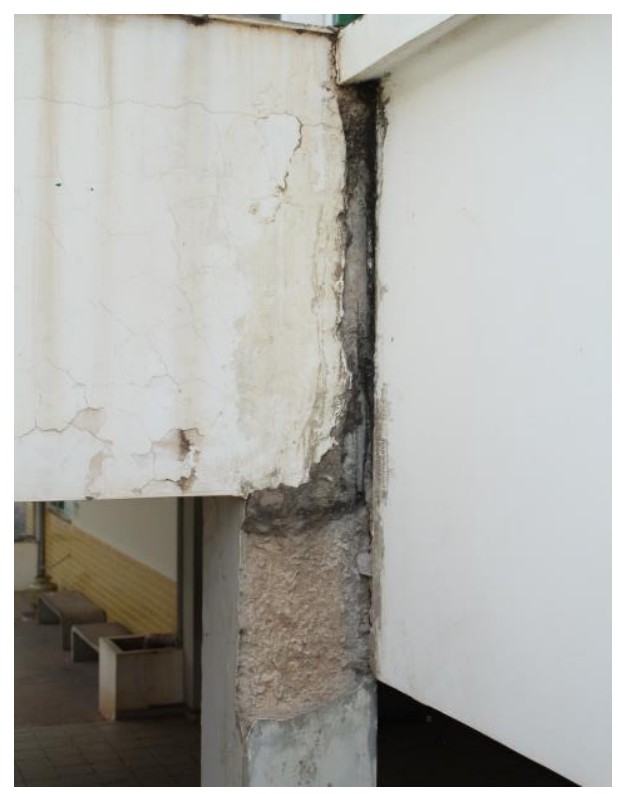

Fissura 12: Fissuras nas junções das vigas e pilares.

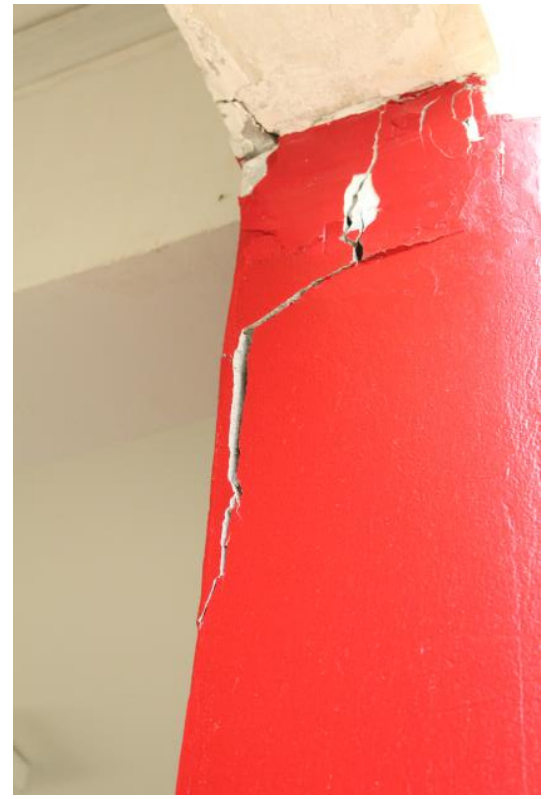

Figura 11: Fissuras no pilar.

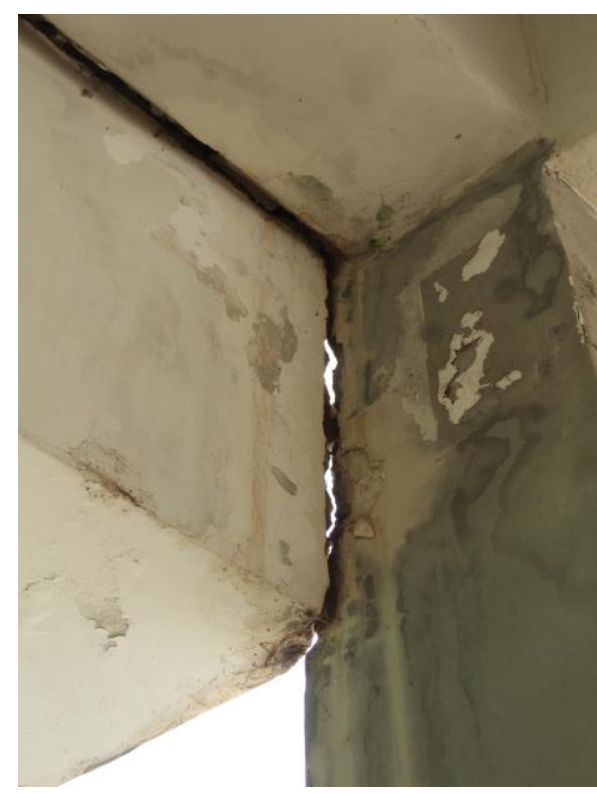

Fissura 13: Fissuras nas junções das vigas e pilares.

Conforme as Figuras 10, 11, 12 e 13, nota-se a presença de rachadura, queda de revestimento, corrosão da armadura, presença de fissuras verticais nas quinas do pilar e fissuras paralelas a armadura longitudinal. Essas fissuras verticais paralelas as armações do pilar levaram a desagregação do concreto. As possíveis causam podem ser diversas, como elas, má execução das peças estruturais, concreto com resistência inadequada, ambiente agressivo, proteção insuficiente, manutenção inadequada. Sendo necessário limpeza rigorosa, recomposição com argamassa ou concreto. 
Além desses pilares, verificou-se que na biblioteca do Campus Aquidauana, dois pilares não foram concretados conforme o projeto. Essa análise foi feita a partir de inspeção visual e tátil. Os mesmos encontram-se como uma seção delgada.

A partir dessas análises, foi questionado sobre como estariam as armaduras no elemento estrutural. Assim, foi utilizado um escâner para concreto com objetivo de auxiliar na determinação da quantidade, posicionamento e diâmetro das armaduras existentes dentro do elemento de concreto inspecionado. Conforme já imaginado, os resultados foram que a execução da estrutura não seguiu as orientações apresentadas no projeto estrutural, com isso, havendo a falta de concreto no interior do elemento estrutural.

\subsection{Manifestações Patológicas na Laje}

\subsubsection{Fissuras}

Foi diagnosticado através de simples inspeção visual uma fissura principal que atravessa todo o bloco de ensino, conforme é 14.

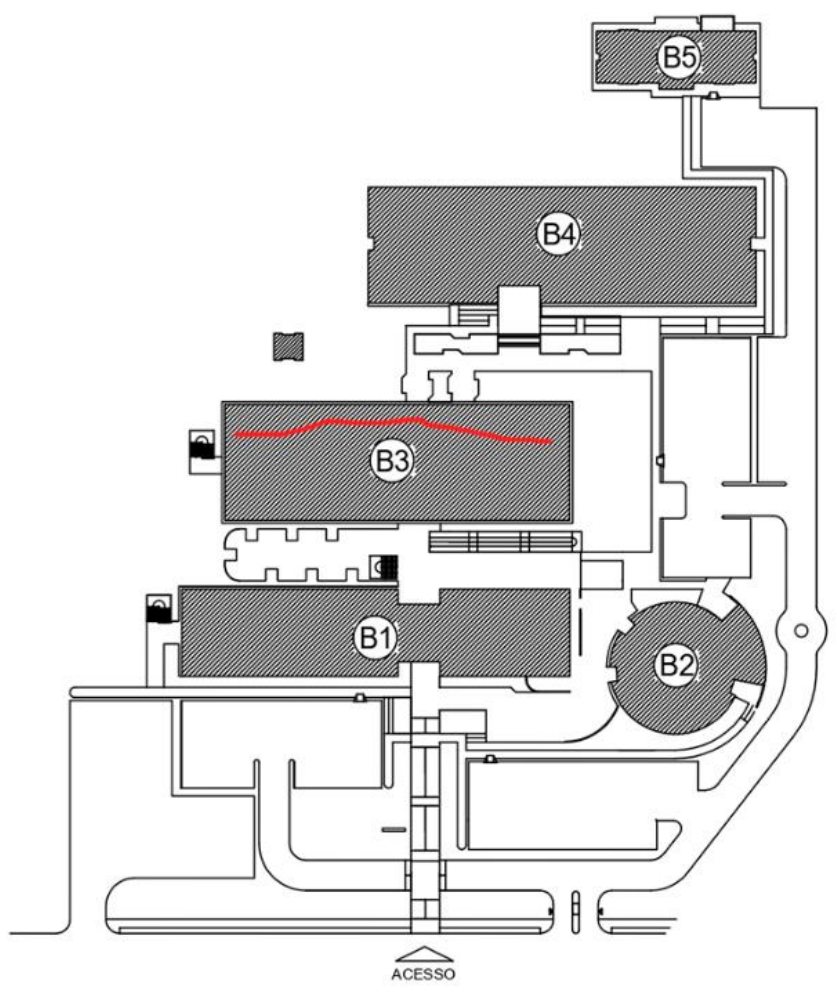

Figura 14: Destaque em Vermelho da Fissura na Laje.

Registrou-se como uma das causas desta manifestação patológica a ausência de uma junta de dilatação apropriada. Considerando que o edifício possui mais que $20 \mathrm{~m}$. Essas juntas de dilatação servem para absorver os efeitos de retração do concreto, ou evitar que os esforços de um elemento afetem outro. A fissura está presente no segundo bloco, na qual, ficam localizadas as salas de aulas. Essa fissura costura o bloco todo, conforme destacado nas Figuras 15 e 16. 


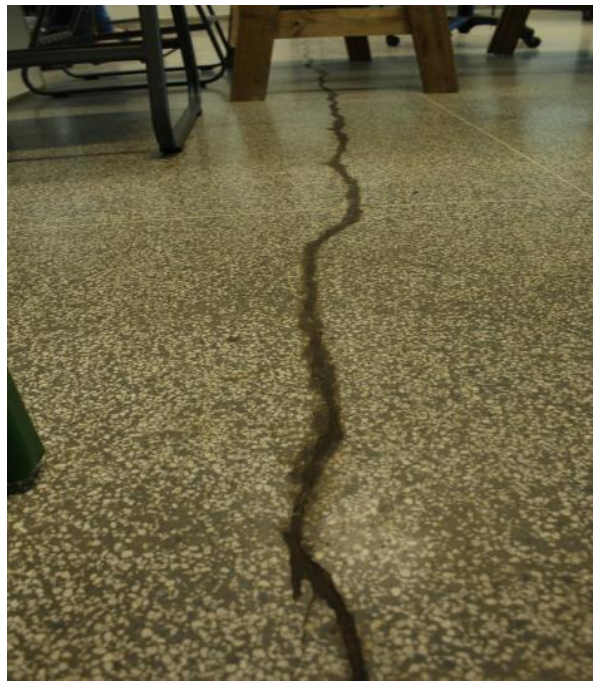

Figura 15: Fissuras na Laje do Bloco de Ensino.

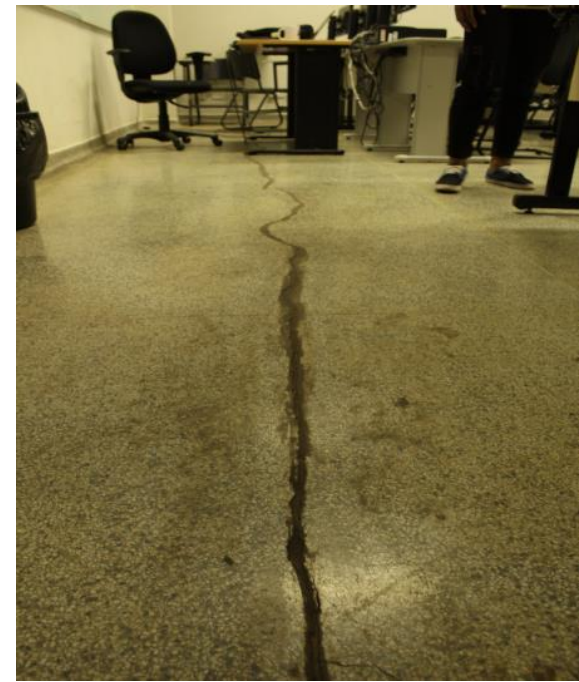

Figura 16: Fissuras na Laje do Bloco de Ensino.

\subsubsection{Infiltrações}

Durante a inspeção da edificação, foram encontrados vários locais com incidência de infiltrações. As causas patológicas variam nas diversas situações. Nas Figuras 17 e 18, observa-se a presença de vários pontos de infiltrações ao longo da laje, havendo indícios de alguns locais com bolores, com isso, comprometendo a estética local e possivelmente a armadura incorporada na estrutura.

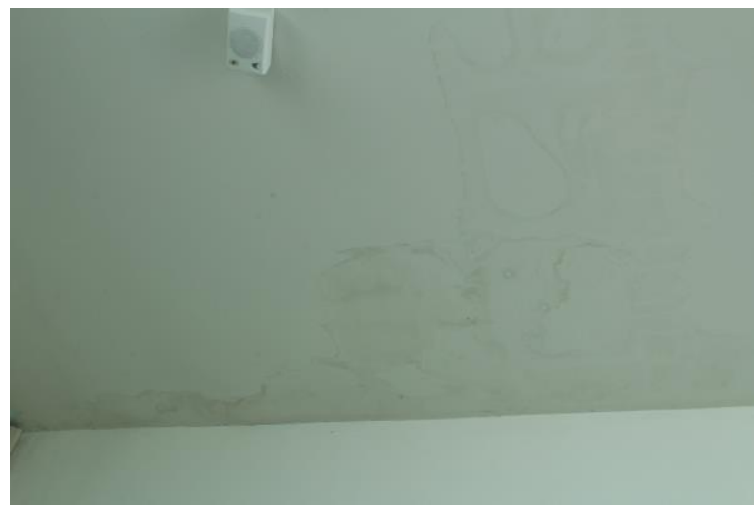

Figura 17: Infiltração na laje.

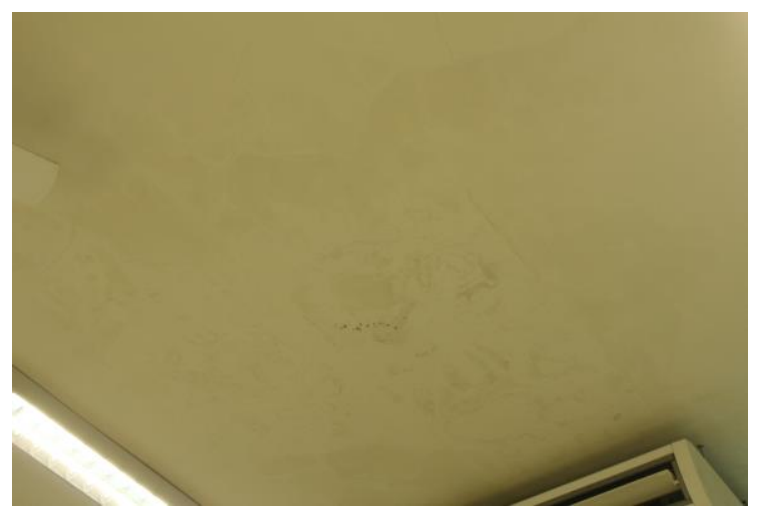

Figura 18: Infiltração na laje

A falta de impermeabilização adequada antes da colocação de revestimentos em lajes e a drenagem incorreta dos fluidos provenientes da chuva, podem ser considerados como possíveis agentes causadores da patologia. Muitas vezes os sistemas de impermeabilização são negligenciados nas construções. O uso de mão de obra sem qualificação e produtos de má qualidade são as maiores causas de falhas na impermeabilização e com ocorrência de infiltrações nas lajes.

\section{CONCLUSÃO}

Diante de todo o exposto, verificou-se em toda a edificação do Instituto Federal de Mato Grosso do Sul, a presença de manifestações patológicas importantes, principalmente fissuras e rachaduras, que propagam-se entre os pilares, as vigas e as lajes da instituição. A maioria das fissuras identificadas podem ter ocorrido durante a execução da obra,pela baixa qualidade do concreto empregado na construção da edificação, falta de armadura e técnicas construtivas. Recomenda-se que essas fissuras sejam tratadas a fim de evitar danos futuros e não comprometer a vida útil do edifício. 


\section{REFERÊNCIAS}

THOMAZ, E.. Trincas em Edifícios: causas, prevenção e recuperação.. 1.ed. São Paulo: Pini, 1989.

CASOTTI, D. Causas e Recuperação de Fissuras em Alvenaria. 2007. 80p. Universidade de São Francisco, Itatiba, 2007. Disponível em: 〈http://lyceumonline.usf.edu.br/salavirtual/documentos/1061.pdf〉. Acesso em: 17 nov. 2019.

NEVILLE, A. M. Propriedades do concreto. 2ed. São Paulo: Pini, 1997. 787 p.

SILVA, L. C. P. F.; HELENE, P. Análise de estruturas de concreto com problemas de resistência e fissuração. In: IBRACON. Concreto: Ciência e Tecnologia. Volume I e II. 1.ed. São Paulo: G.C. Isaía, 2011. 1956 p.

TUTIKIAN, B; PACHECO, M. Inspeção, Diagnóstico e Prognóstico na Construção Civil. Boletim Técnico Alcopat Brasil, 2013, 17p.

VERÇOZA, E. J. Patologias das edificações. Porto Alegre: Sagra, 1991, 9p.

MARCELLI, Maurício. Sinistros na construção civil: causas e soluções para danos e prejuízos em obras. 2007. São Paulo: Pini. ISBN 978-85-7266-178-2

MAGAlHAES, Ernani F. Fissuras Em Alvenarias: Configurações Típicas e levantamento De Incidência No Estado Do Rio Grande Do Sul. 2004. Dissertação De Mestrado. Universidade Federal Do Rio Grande Do Sul. Escola De Engenharia. Curso De Mestrado Profissionalizante Em Engenharia. Porto

VANINI, Eduardo. Ataques de cupins comprometem até a estrutura dos imóveis. O Globo, Rio de Janeiro, 25 de setembro de 2016. Disponível em: https://oglobo.globo.com/rio/ataques-de-cupins-comprometem-ate-estrutura-dosimoveis-20169774 Acesso em: 10 de outubro de 2019.

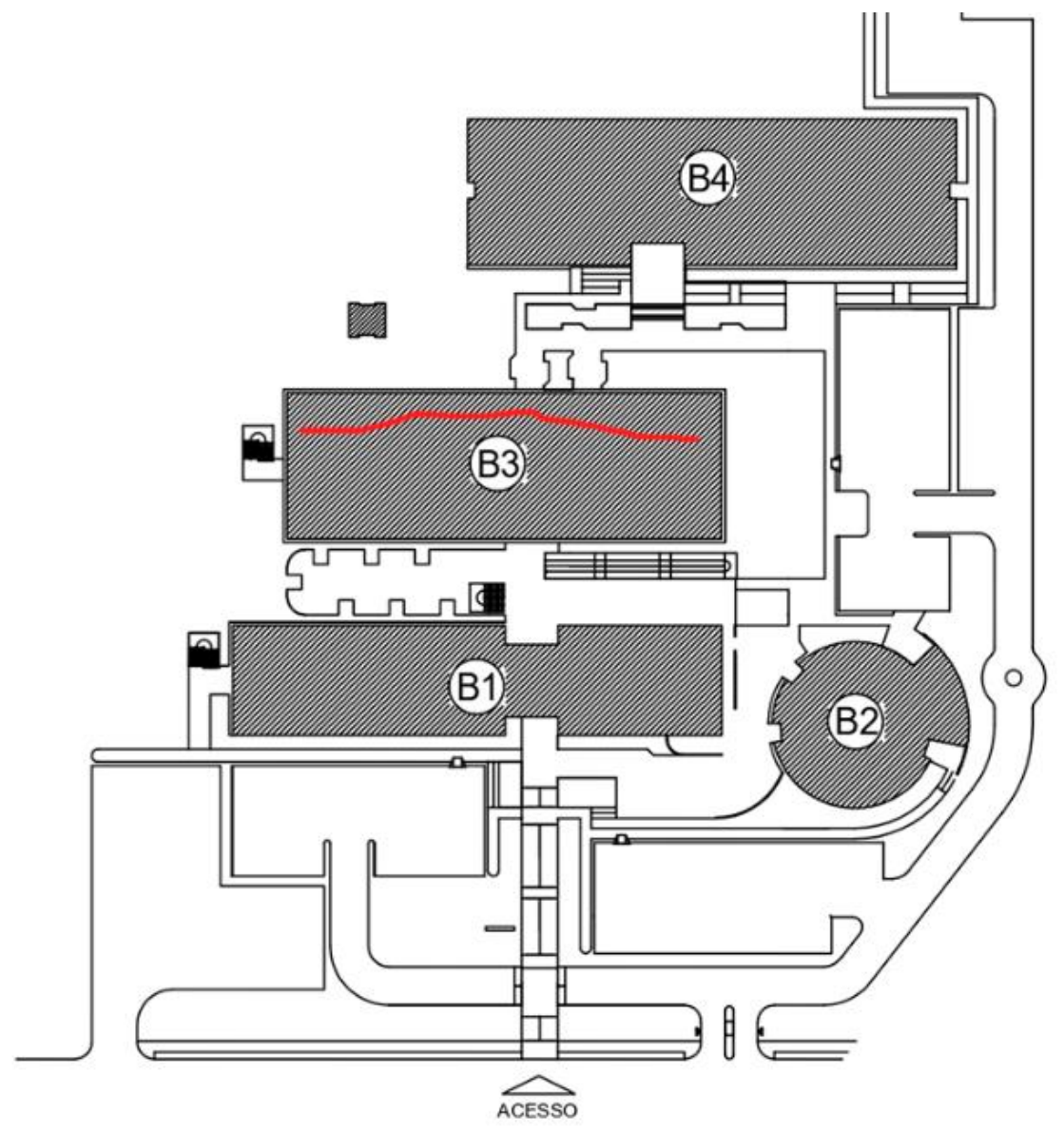

